\title{
Juvenile and late forms of amaurotic idiocy in one family
}

\author{
WOLFGANG ZEMAN ${ }^{1}$ AND JULIUS HOFFMAN \\ From the Department of Psychiatry and the Graduate School, Ohio State \\ University, Columbus, Ohio, U.S.A.
}

Amaurotic idiocy is conventionally defined as a genetically controlled sphingolipidosis which occurs in five forms of which the common denominator is a distension of the body of the nerve cell by the accumulation of lipids. The variants are distinguished not only by the age of onset of the first symptoms but also by certain clinical features and by differences in the tinctorial and physico-chemical qualities of the 'stored' lipids. Thus, Sandifer (1959) lists the congenital, infantile, late infantile, juvenile, and the adult types.

Many investigators are of the opinion that the various types are nosologically related and together form one disease entity. Seitelberger, Vogel, and Stepan (1957-58) suggested that the variants were the expression of different intensities of a qualitatively identical genetically controlled disturbance, whereas Diezel (1960) asserted that the different forms of amaurotic idiocy were but age-dependent variants. Friedrich (1957) and Cumings (1961) also considered the amaurotic idiocies to represent one entity and the same view was expressed by Escolá (1961) on the basis of a comparative histological and histochemical study of 19 cases.

On the other hand, a number of authors favour the hypothesis that juvenile and infantile amaurotic idiocy are different (Hoffman and Riepenhoff, 1957). The most outspoken proponent of this view was originally Spielmeyer (1905), who stated that juvenile amaurotic idiocy had 'nothing to do' with TaySachs disease, clinically as well as pathologically. In his later writings, however, Spielmeyer (1922) considered the two conditions to be related. Recently Wolman (1961) suggested that the amaurotic idiocies might not constitute a nosological entity but rather a morphological syndrome representing different metabolic derangements. Jervis (1959) did not take a definite position in this argument yet he stressed the biochemical differences between the two forms. Norman (1958) favoured a clear-cut dis-

${ }^{1}$ Present address: Indiana University Medical Center, Indianapolis 7, Indiana, U.S.A. tinction between infantile and juvenile amaurotic idiocy.

For the nosological classification of the various forms of amaurotic idiocy, genetic studies are of particular relevance. As early as 1931, Sjögren studied 53 families in southern Sweden with a total of 120 instances of juvenile amaurotic idiocy. He drew attention to the somewhat characteristic clinical picture of the disease, to the relatively wide fluctuations of the age of incidence of the various symptoms, and of the age of demise. After a careful and well-controlled evaluation of his material, Sjögren came to the conclusion that juvenile amaurotic idiocy must be considered different from infantile amaurotic idiocy because of its hereditary features. Hanhart (1954), after a similar study of 27 families with cases of infantile amaurotic idiocy, concluded that this condition was a disease sui generis. Likewise, Wyburn-Mason (1943) proposed that amaurotic idiocy existed in two distinct types, namely, the infantile, which is probably related to NiemannPick's disease, and the juvenile form. There is general agreement that the infantile form affects predominantly, but not exclusively, descendants of eastern European Jews, whereas the juvenile form has apparently never been found in this ethnic group. The four Jewish sisters described by Higier (1897), first interpreted by Vogt (1909) and later quoted by Wyburn-Mason (1943) as having been afflicted with juvenile amaurotic idiocy, most probably had a familial spastic lateral sclerosis. The apparent nosological disunity of infantile and of juvenile amaurotic idiocy is further supported by the fact that no instance is on record in which the two conditions affected different members of the same family. The ostensible exception to this rule reported by Bertrand and van Bogaert (1934) was later found to represent an error in diagnosis (van Bogaert, 1953).

In contrast, the precise nosological positions of the congenital, the late infantile, and the adult types of amaurotic idiocy have not yet been fully clarified 
by genetic studies. The extreme rarity of the congenital type precludes pertinent investigations at the present time. That late infantile amaurotic idiocy may not deserve a separate status was first suggested by Wyburn-Mason (1943) and subsequently endorsed by van Bogaert (1953). Apparently instances of this variant represent either delayed forms of the infantile type or precocious forms of the juvenile. This view is shared by Norman (1958). With regard to adult amaurotic idiocy, Hallervorden (1938) suggested that some patients with this type actually suffer from an early variant taking an extremely protracted course with the onset of symptoms in infancy or childhood and death occurring during adult life. On the other hand, there are 'true adult' cases in which signs of the disease do not become manifest until the patient has entered adult life, and sometimes such patients may reach their 40 s before they show any symptoms at all (Kufs, 1931; Fine, Barron, and Hirano, 1960). Adult amaurotic idiocy (some 20 cases have been reported to date) is known to have affected several members of one sibship (Kufs, 1925; Wagner, 1949; Allegranza, 1956) but its concordance with the infantile or the juvenile type in the same family has never been established beyond doubt It therefore appears justified to report on two siblings with Batten-Spielmeyer-Vogt's disease and on their paternal grandaunt who suffered from what appears to be the adult type of this condition. The clinical manifestations of all three cases have been previously described and it has already been suggested that juvenile and adult forms of amaurotic idiocy are related, although modified, expressions of the same process (Hoffman, 1958). This relationship was emphasized by designating both forms 'pigmentary retinal lipoid neuronal heredodegeneration'. The present report supplements these earlier observations with a histological and histochemical study.

\section{CASE REPORTS}

CASE 1 This was a 53-year-old unmarried woman whose clinical findings were described in detail by Hoffman (1958). In summary, she was healthy until she was 18 years old when she experienced transient motor disturbances and ataxia. She was of superior intelligence until 29 years old when she began to display a progressive central nervous system dysfunction. Her social judgment, intelligence, and motor function deteriorated. There was optic atrophy with retinitis pigmentosa. No extrapyramidal or cerebellar signs were observed. She died from cardiac decompensation. The mental illness lasted for 24 years.

The body had been embalmed before necropsy. The brain weighed 1,000 grams. Although appearing atrophic, the brain otherwise was normal externally, except for a nodule $0.5 \mathrm{~cm}$. in diameter protruding from the posterior part of the hypothalamus into the interpeduncular cistern. The lept omeninges were translucent. The basal arteries were free of arteriosclerotic changes and patent.

A moderate hydrocephalus ex vacuo was seen in coronal sections. Histological examination showed a hamartoma in the floor of the third ventricle consisting of vascular tufts and abnormally shaped and arranged neurons. It had not encroached upon the hypothalamic structures. Apart from this lesion, there was a widespread accumulation of lipid substances in most of the nerve cell bodies, and, in some regions, in the astrocytes. There was diffuse gliosis of the white matter but no demonstrable demyelination.

CASE 2 This patient was Bonnie Z. described by Hoffman and Riepenhoff (1957) as an instance of juvenile amaurotic idiocy. She had her first convulsion at $5 \frac{1}{2}$ years of age and died at 17 years of age.

At necropsy, the entire brain, including the brain-stem and cerebellum, was greatly atrophic, weighing only 640 grams. The leptomeninges were translucent. After a midsaggital cut, one-half of the brain was deep frozen immediately and the other half was fixed in formalin. After fixation, the hemisphere was cut in frontal sections. The cortex was atrophied all over and measured an average of 2 to $3 \mathrm{~mm}$. in width. The basal ganglia were small. The territory covered by the white matter was proportionally reduced. The ventricular system was dilated with the angles blunted. The average width of the lateral ventricles was $3 \mathrm{~cm}$. The brain-stem and cerebellum were very small and atrophic but well proportioned.

Histological examination showed that practically all neuron bodies were severely distended with lipid deposits. The number of Purkinje cells was greatly reduced and cerebellar granule cells had almost disappeared. The white matter showed diffuse loss of myelinated fibres and fibrillary gliosis.

CASE 3 Lynn $Z$. was the younger sister of the preceding patient, also described by Hoffman and Riepenhoff (1957) as a classic example of juvenile amaurotic idiocy. She showed the first signs of a central nervous system deterioration at the age of 8 and died at 14 years of age.

At necropsy, the brain was markedly atrophic, weighing 600 grams. The leptomeninges were translucent. One-half of the brain, including the brain-stem and cerebellum, was deep frozen and the other half was fixed in formalin. On coronal sections, the width of the cerebral cortex was found to average $2 \mathrm{~mm}$. The basal ganglia were reduced in size, as was the white matter. The lateral ventricle was dilated, with an average lateral width of $3 \mathrm{~cm}$. No focal lesions were encountered. The cerebellar folia were markedly atrophic and sclerosed and the brain-stem was extremely small.

Histological examination showed the nerve cell bodies to be everywhere distended by an accumulation of lipid material. The cerebellar cortex contained practically no granule cells, and most of the Purkinje cells had disappeared. There was a diffuse loss of myelinated fibres throughout the white matter and a corresponding fibrillary gliosis. 


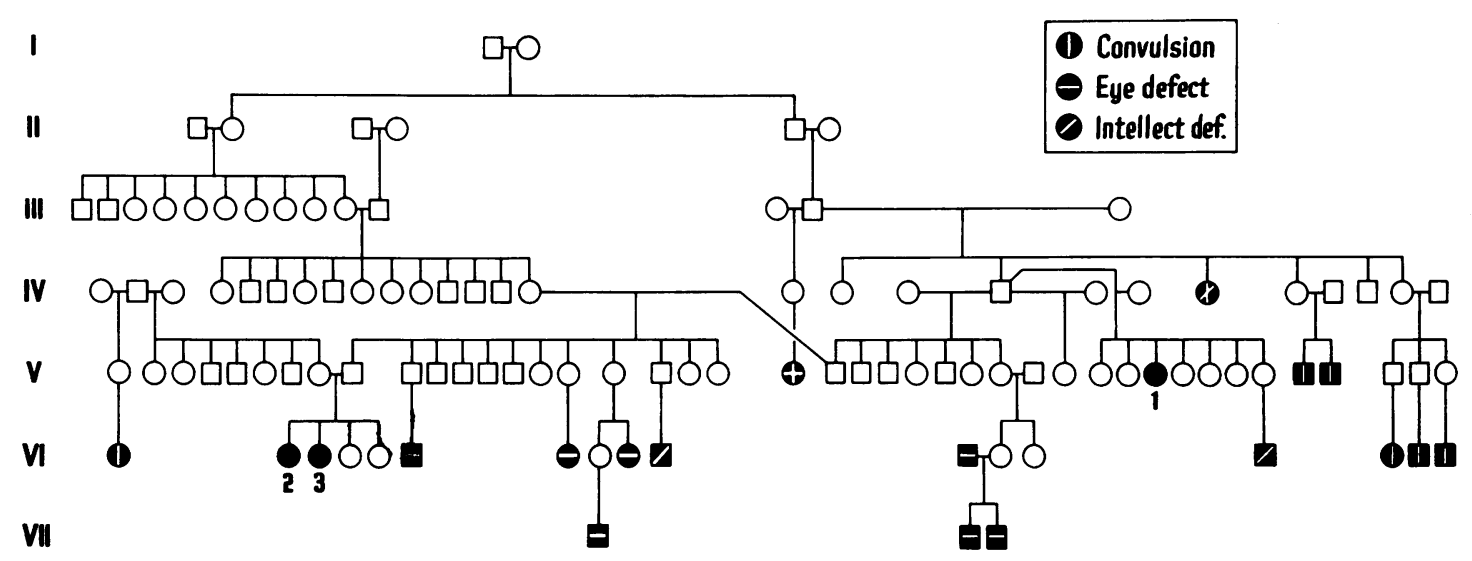

FIG. 1. Pedigree of family $Z$. The numbers refer to the patients discussed in this report.

The precise genetic relationship between the three patients is depicted in Figure 1. Consanguinity in this family of German, Scottish, and Irish stock is noteworthy. In addition to the probands, many other members of this family were afflicted with neurological defects. For lack of clinical information and of necropsy studies, no effort is made to speculate on a diagnosis of these cases. In view of a similar observation by Ponga (1960) the combination of juvenile amaurotic idiocy with oligophrenia, visual defects, and convulsive disorders may, however, be significant

BIOCHEMICAL AND HISTOLCGICAL STUDIES

BIOCHEMICAL STUDIES Fresh unfixed and formalinfixed cortical tissue of Cases 2 and 3 was examined for neuraminic acid content using the methods of Klenk and Langerbeins (1941) and of McCluer, Coram, and Lee (1962), and for hexosamine content using the procedure of Svennerholm (1956). These studies were performed in this laboratory by Dr. R. McCluer. Corresponding specimens were similarly examined at Letchworth Village by Dr. Jervis. In both laboratories no abnormalities in the content of the two compounds were found.

HISTOLOGICAL AND HiSTOCHEMICAL STUDiEs After a routine histological examination of sufficient extent to establish the diagnosis, a histochemical study was undertaken with the aim of obtaining a basis for comparison of the nature and distribution of the accumulated lipids in the three brains. For this purpose, corresponding tissue blocks of all three cases were taken from 22 representative areas of the central nervous system. These blocks were cut in half; one piece was embedded in paraffin and the other kept in formalin for frozen sections. The corresponding pieces from each of the cases were embedded in one block and cut. Thus, identical topographical structures from each of the three brains were mounted on the same slide. By using this precaution, variability resulting from technical factors in the histochemical procedures could be kept at a minimum.

\section{RESULTS}

The distribution and the degree of the lesions as judged from sections stained with cresyl violet and with haematoxylin and eosin are presented in Table I. As can be seen, the extent and degree of neuronal lipid accumulation in brain 1 were much less than in brains 2 and 3 . On the other hand, practically all neurons of brain 1 , with the exception of those in the cerebellar cortex, were altered in some way. Most neurons contained few, if any, Nissl bodies. The characteristic foamy transformation of the cytoplasm, however, was seen only occasionally in brain 1, whereas it was a common finding in brains 2 and 3. The accumulation of intraneuronal lipids did not reach the proportions commonly encountered in infantile amaurotic idiocy and in gargoylism, referred to as 'ballooning'. There was a diffuse loss of neurons most pronounced in brains 2 and 3, with a corresponding fibrillary gliosis.

The following observations on the distributional pattern of neuronal changes appear to be the most important.

1 A diffuse generalized alteration of nerve cell bodies was seen due to the intracellular accumulation of lipids in brains 2 and 3, compared with a diffuse alteration of practically all nerve cells with intraneuronal lipids more or less restricted to the subcortical gray matter and the paleocortex in brain 1 . 2 Cerebellar granule cells were completely lost in brains 2 and 3 but were preserved in brain 1 . 3 Purkinje cells were largely lost in brains 2 and 3 without definite evidence of lipid accumulation in the 
TABLE I

DISTRIBUTION OF LIPID ACCUMULATION IN NERVE AND VISCERAL CELLS

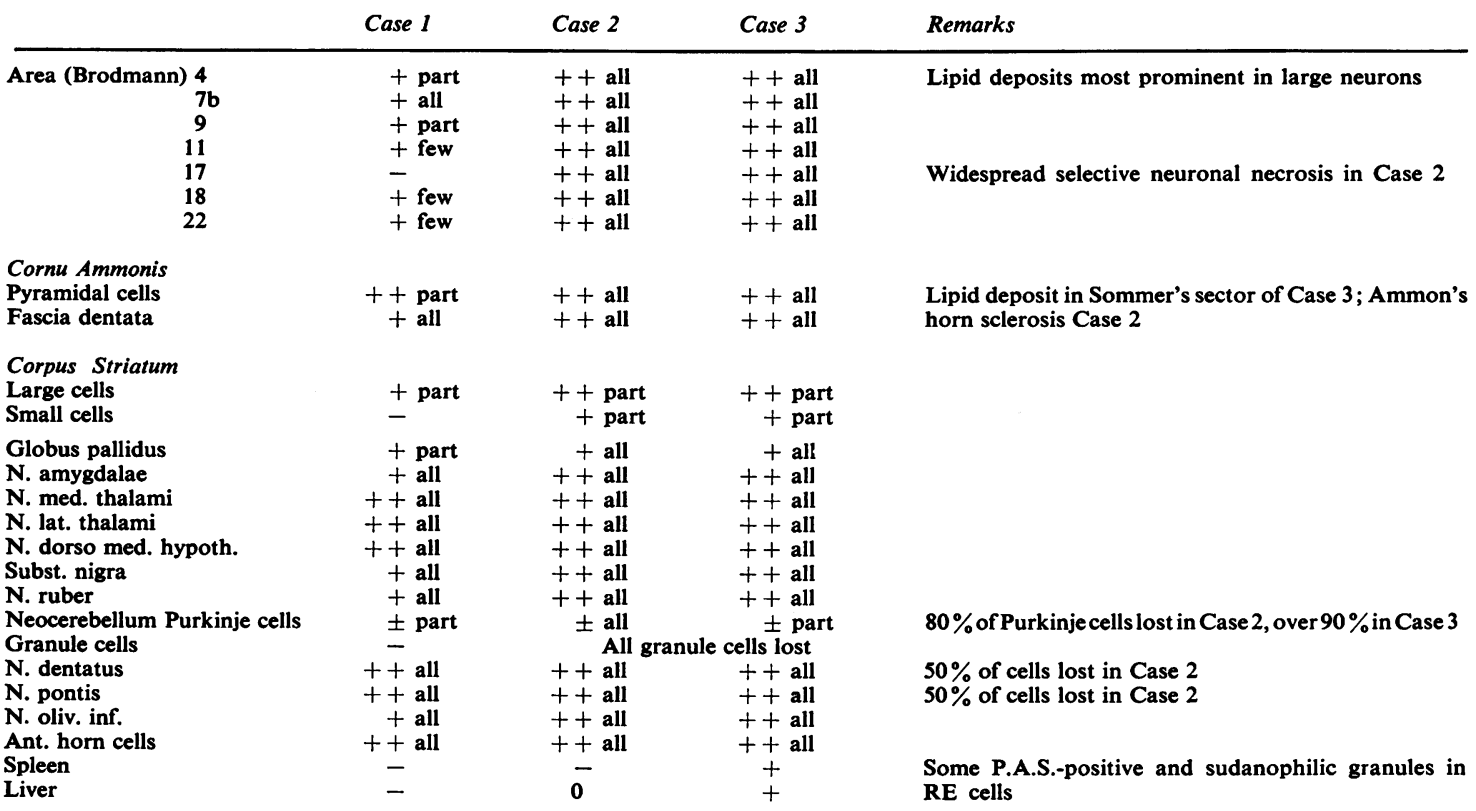

Explanation: ++ cells distended by lipids

+ cells contain lipids, are not distended

\pm cells contain questionable lipids

- cells contain no lipids

0 not examined

'All', 'Part', 'Few' refer to the relative number of cells affected.

surviving elements compared with the full preservation and normal appearance of these cells in brain 1. 4 The fascia dentata in all three brains were involved as were Sommer's sector and the subiculum in brain 3 (Figs. 2 and 3 ).

Although one may agree with Jervis (1959) that too much emphasis is being placed on histochemical studies in amaurotic idiocy, a fairly extensive analysis was performed on paraffin-embedded and frozen sections. It was felt that the genetic relationship warranted this effort because of the assumption that the same enzymatic deficit was operative in all three patients. The more important reactions and the results on four selected types of neurons are summarized in Table II, and Figs. 4 to 9 are photographs of the histochemical reactions of neurons of the dentate nucleus.

On comparing brains 1,2 , and 3 , one easily recognizes a quantitative and qualitative fluctuation of the histochemical reactions. They are not only noticeably different between the three brains but also within the same brain from one neuron type to another, between different neurons of the same topistic unit, and even within the same cell. While the distended neuron bodies stained consistently with PAS and the Sudans, indicating the presence of a glycolipid, affinity for iron haematoxylin, Luxol fast blue, and Amino black B10 gave much more variable results, ranging from negative to strongly positive. Sudanophilia, solubility in non-polar solvents, and Amino black B10 sorbency of the accumulated lipids are generally considered to be interrelated and to express the ratio of proteinbound to free lipids (Seitelberger et al., 1957-58; Diezel, 1960). In the present brains such a correlation was not consistent. The situation in the fascia dentata nerve cells may serve as an example. The sudanophilic material of brain 1 had completely disappeared after paraffin embedding, whereas that of brains 2 and 3 remained in situ after this procedure. The adsorption of Amino black B10 to the fascia dentata neurons was slight in all brains. Similar behaviour was seen in the neuron bodies of the dentate nucleus (Figs. 4 to 9), where sudanophilia after paraffin embedding was ubiquitous in contrast to Amino black B10 staining which was spotty.

Of all the various histochemical and physicochemical tests, acid-fastness and primary fluorescence 

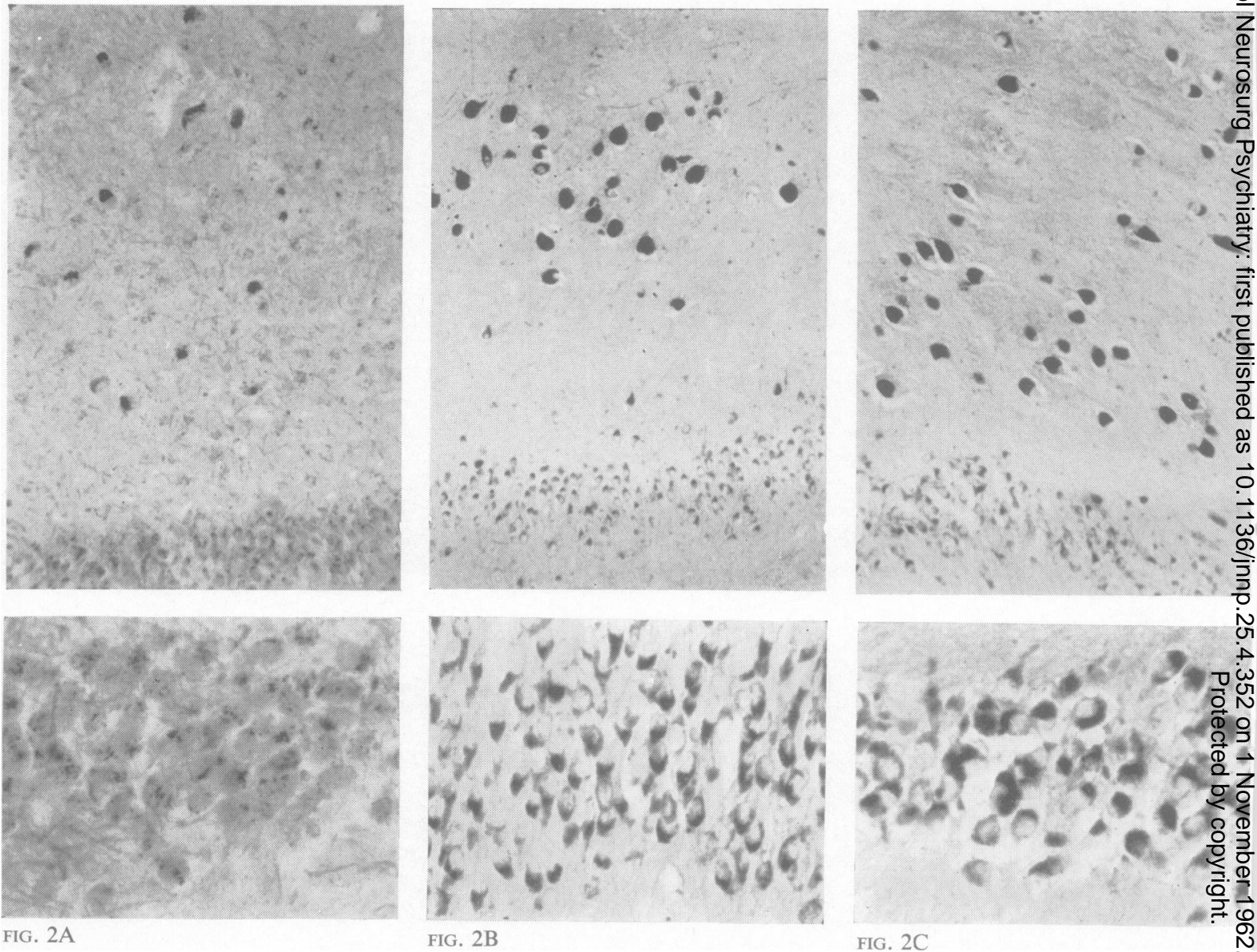

FIG. 2. Fascia dentata; Sudan Black B; top $\times 96$, bottom $\times 240$. A: brain 1, frozen section. B: brain 2, paraffin section. C: brain 3, paraffin section. The sudanophilic intraganglionic granules in brain 1 were fat soluble.

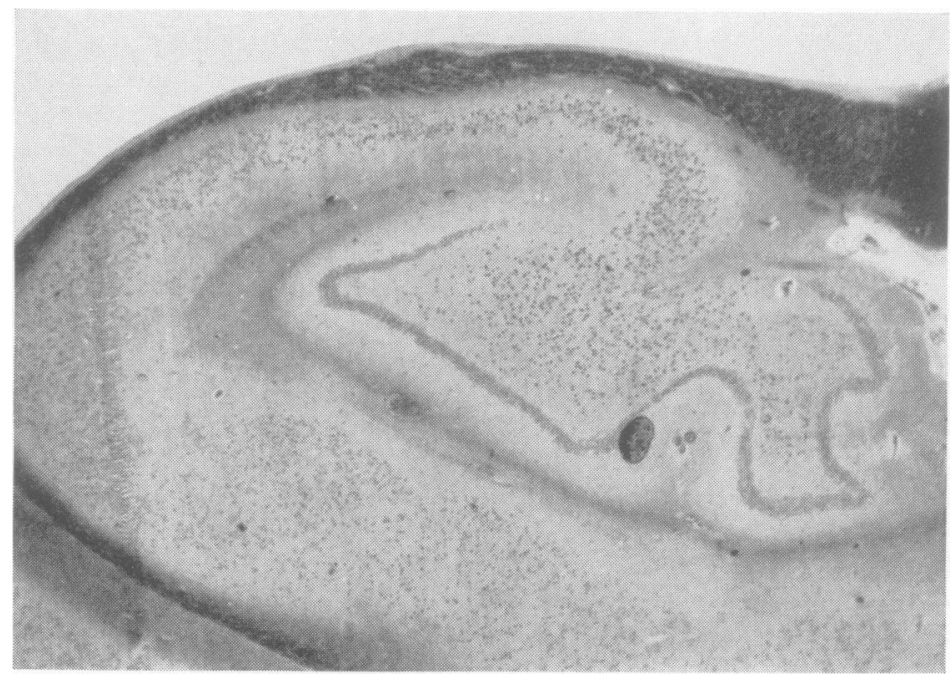

FIG. 3. Cornu Ammonis brain 3. Sudan black $B$ on paraffin section; $\times 12$. Note involvement of Sommer's sector (field $h_{1}$ ). 
FIGS. 4 to 6 . Dentate nucleus; paraffin sections; $\times 240$.
A: brain 1 .
B: brain 2.
C: brain 3 .
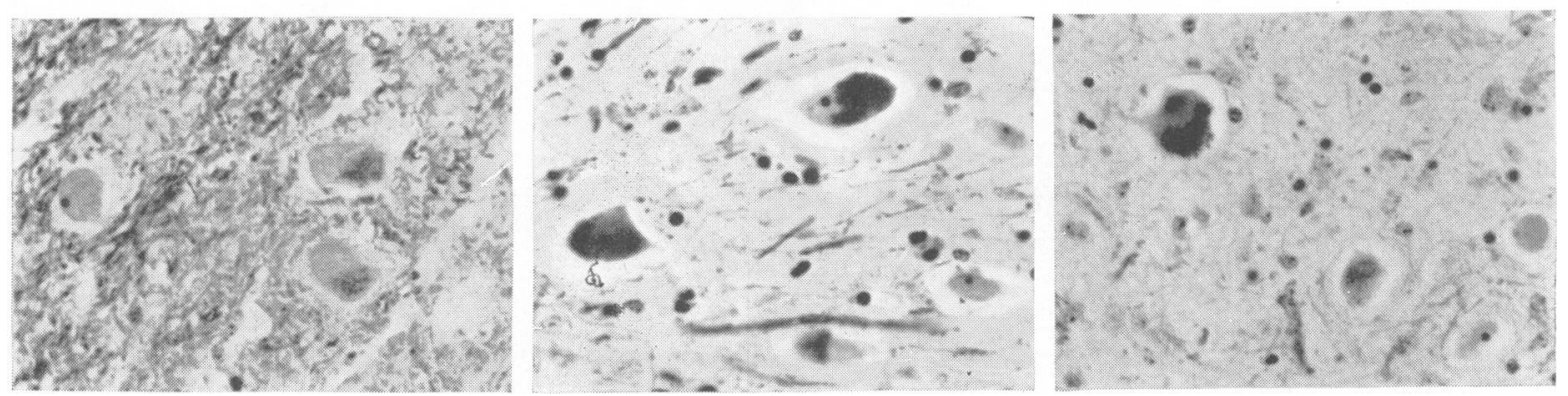

FIG. 4. Iron haematoxylin. Note the granular appearance of the intraganglionic lipids and their uneven distribution in comparison with the sudanophilic granules in Fig. 6.
A: brain 1 .
B: brain 2.
C: brain 3.
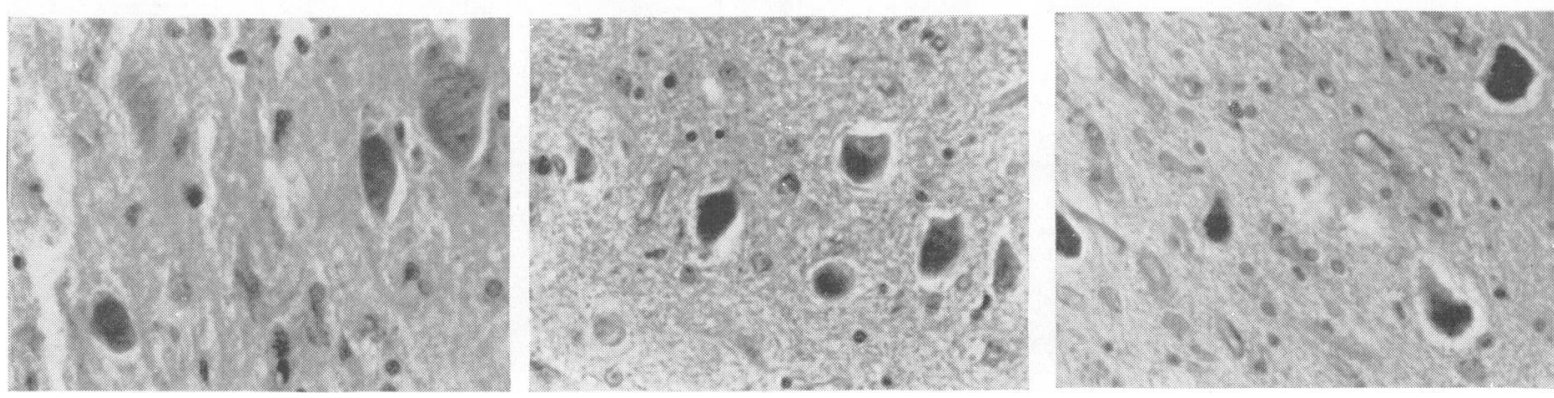

FIG. 5. P.A.S.-positive material is seen in granular form in brain 1 both in neurons and astrocytes. Diffuse staining of the neurons in brains 2 and 3.
A: brain 1 .
B: brain 2 .
C: brain 3.
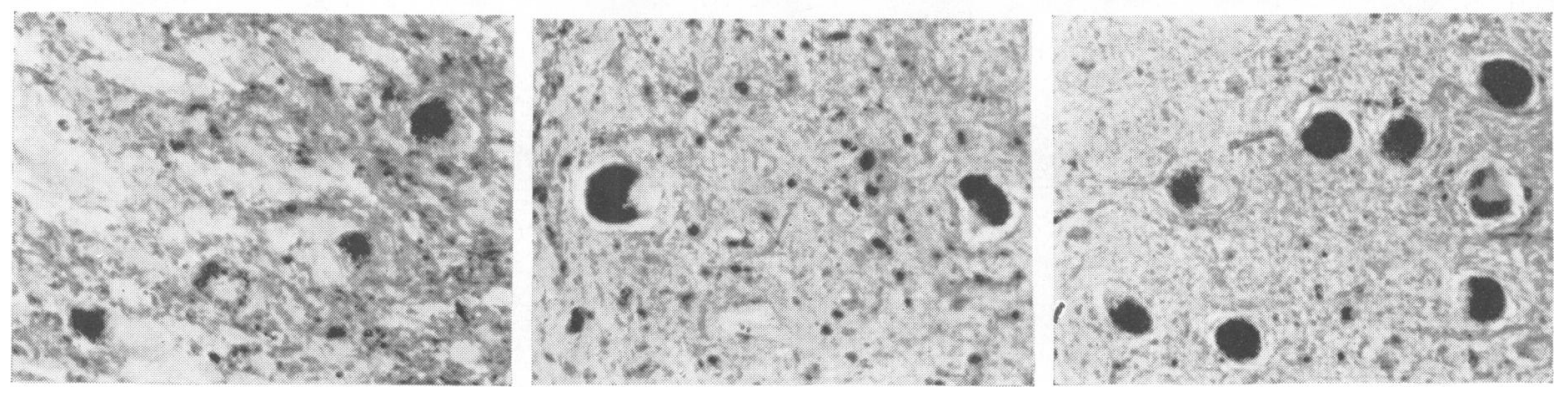

FIG. 6. Sudan black B. Sudanophilic granules are also seen in astrocytes. 
FIGS 7 to $9 . \quad$ Dentate nucleus; paraffin sections; $\times 240$.
A: brain 1 .
B: brain 2.
C: brain 3 .
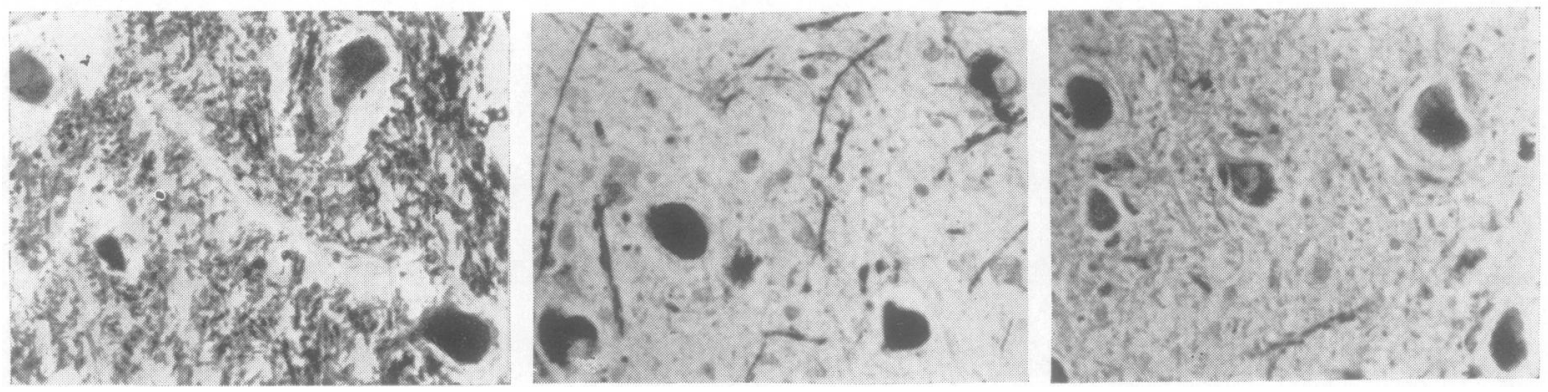

FIG. 7. Luxol fast blue. Note the variable staining of neurons.

A: brain 1 .

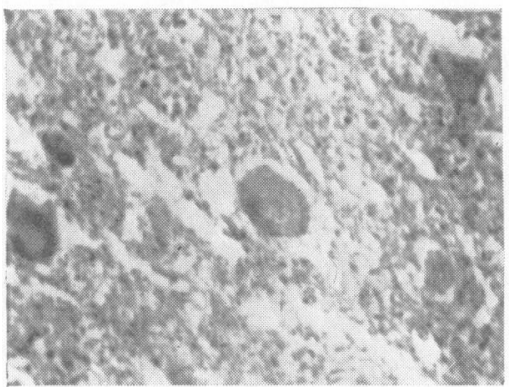

B: brain 2

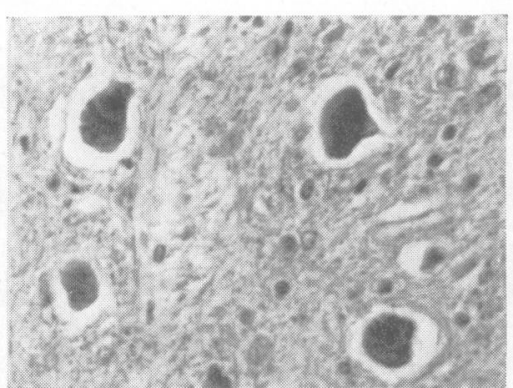

C: brain 3.

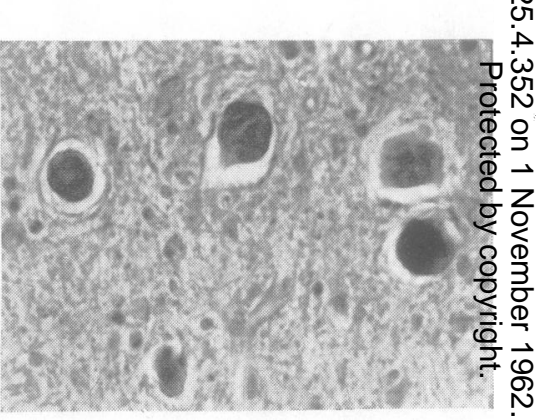

FIG. 8. Amino black B 10. Note the variable and diffuse staining of the neurons in all three brains.

\section{A: brain 1 .}

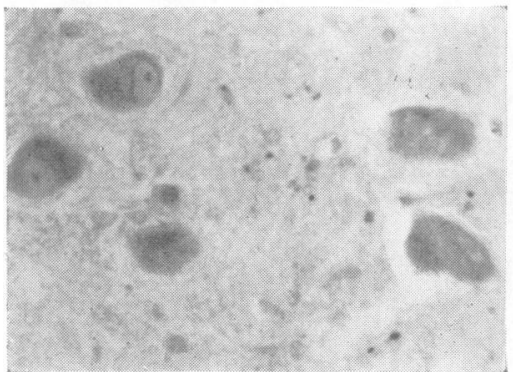

B: brain 2 .

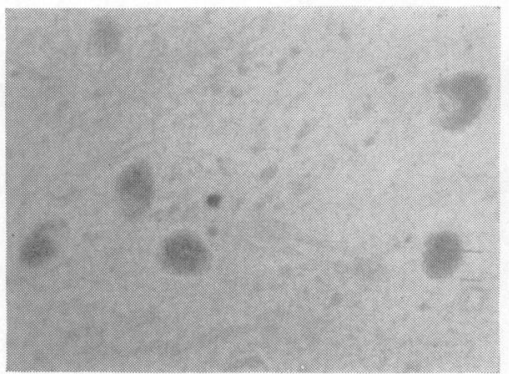

C: brain 3.

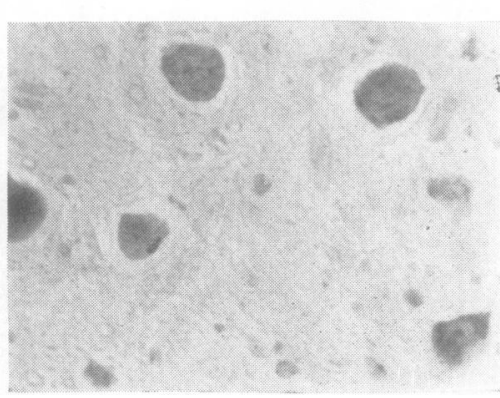

No

FIG. 9. Acid-fast stain. Note the small size of the granules with this stain in comparison with the sudanophilic granules and the granules demonstrated by iron haematoxylin and Luxol fast blue. 
TABLE II

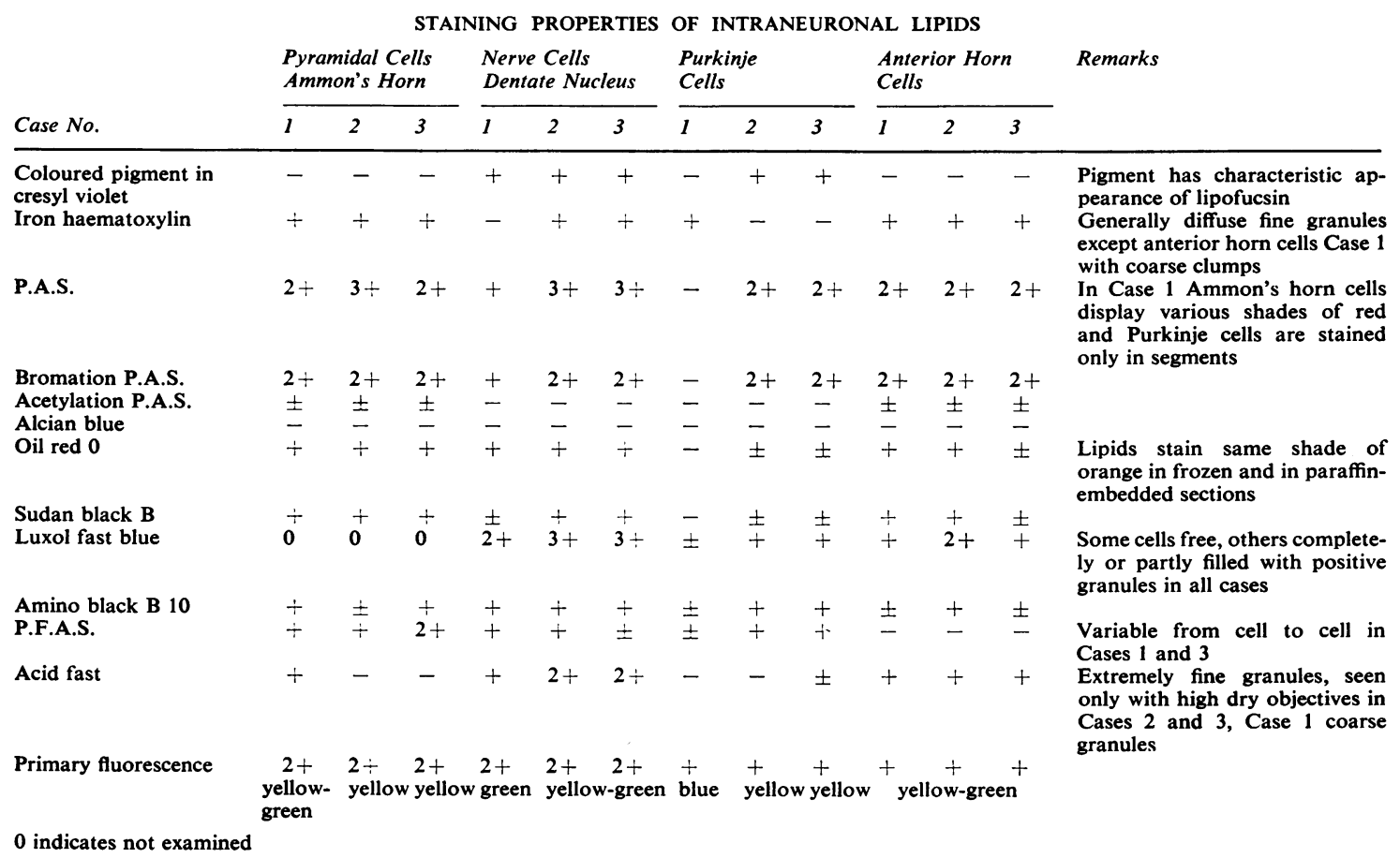

correlated best. Wherever minimal amounts of acid-fast lipids were found, the cells gave a primary yellow-greenish fluorescence. With increasing size of the acid-fast granules, the colour of the fluorescence shifted toward green, indicating the presence of lipofucsin.

In summary, the following points on the histochemical observations can be made:

1 All three brains are characterized by intraneuronal accumulations of glycolipids, frequently associated with proteins and often giving positive reactions for lipofucsin. 2 These glycolipids exhibit different staining reactions from one cell to another within the same topistic unit, as well as within different segments of the same cell. They occur in a spectrum of shapes, ranging from a homogeneous distribution to the formation of coarse granules several microns in diameter. 3 Interstitial glial elements contain lipids similar to those found in the neurons, in brain 1 even in areas without definite lipid accumulation in nerve cell bodies.

\section{DISCUSSION}

CLINICAL CONSIDERATIONS As pointed out by Hoffman (1958), the diagnosis in Case 1 was made on the basis of the clinical findings together with the genetic connexion with proven cases of the juvenile type of amaurotic idiocy. It is recognized that in contrast to the infantile and juvenile forms, late amaurotic idiocy does not display a diagnostic clinical pattern. A remarkable feature of this case is the diminished visual acuity with primary optic atrophy and signs of retinitis pigmentosa. This is quite uncharacteristic for the late form, for which reason Fine et al. (1960) refrain from using the term amaurotic idiocy. Absence of visual difficulties and of objective signs of retinal lesions are even considered to favour a diagnosis of late amaurotic idiocy (van Bogaert and Borremans, 1937). Although cerebellar and extra-pyramidal signs are common in adult amaurotic idiocy, their absence in Case 1 does not militate against the diagnosis, because other instances are known in which these findings were lacking (Kufs, 1931).

Because of the genetic connexion with juvenile amaurotic idiocy, one must ask whether Case 1 had a protracted form of this condition. In keeping with presently accepted definitions, it should be classified as an adult form since the patient did not show signs of nervous system disease until age 29, except for a brief episode of motor disturbance and ataxia at age 18 , from which she fully recovered.

Cases 2 and 3 presented the classic picture of 
juvenile amaurotic idiocy with intractable seizures, blindness, and severe progressive dementia terminating in a state of clinical decortication.

PATHOLOGICAL CONSIDERATIONS The hypothalamic hamartoma in brain 1 obviously cannot account for the clinical signs. Thus it appears safe to regard it as an incidental finding.

Whereas the histopathological diagnosis of juvenile amaurotic idiocy in Cases 2 and 3 is manifest, the diagnosis of adult amaurotic idiocy in Case 1 is somewhat problematic. In fact, this case posed diagnostic difficulties commensurate to, if not greater than, those of the patient of van Bogaert and Borremans (1937) because of the paucity of nerve cells distended by lipid deposits. However, considering the extent of lipid accumulation in the lipophobe cells, the diagnosis is well founded.

A number of observations made on this case require further discussion. The widespread, almost universal morphological alterations of nerve cells despite the absence of lipid accumulation in part of them is difficult to explain. Admittedly, this brain was not optimally fixed due to prior embalming, and it may be argued that the nerve cell changes represent artefacts. The possibility of ischaemic nerve cell damage on account of chronic cardiac decompensation with prolonged agony must also be entertained, but it is supported neither by the cytopathomorphology nor by the distribution of the lesions. A third alternative is the assumption that cytoplasmic nerve cell degeneration has preceded the accumulation of lipids. As is well known, this hypothesis was first developed by Schaffer (1930) but fell in disrepute largely on the strength of Spielmeyer's (1929) forceful arguments.

Another intriguing finding is the occurrence within neuroglial cells, especially astrocytes, of lipids having the same staining and physicochemical qualities as those seen in neurons. While such findings may be expected in regions of neuronal loss, their presence in the cerebellar cortex of Case 1 with no appreciable parenchymal damage cannot be explained this way. It will be recalled that Sjövall (1934) interpreted this finding as an indication that the metabolic disturbance of amaurotic idiocy affects not only nerve cell bodies but also neuro-ectodermal glial elements, in particular astrocytes.

The observation on the randomized histochemical behaviour of the ganglionic lipids conforms to the results on similar material by other authors. The variability of the staining and physico-chemical properties of the accumulated lipids has been the subject of much speculation. Diezel (1957) asserts that tinctorial differences express the ratio of ganglioside to sphingomyelin which decreases steadily with increasing age. Seitelberger et al. (1957-58) found three different lipid fractions in amaurotic idiocy, distinguished by solubility and the ability to take up stain, and occurring in one and the same cell in varying ratios. The lipid soluble fraction I, according to these authors, decreases proportionally with the intensity of the process and is practically absent in the juvenile and adult forms. In the present cases this was not the rule; for example, the lipid accumulated in the neurons of the fascia dentata of the adult brain was soluble in contrast to the lipid of the juvenile brains. It has also been suggested that in juvenile amaurotic idiocy a large part of the accumulated lipids is ganglioside (Diezel, 1957). Biochemical studies on our material did not show an increase of neuraminic acid and of hexosamine which indicates that no excess ganglioside was present. Other authors were also unable to find an increase of ganglioside in brains with juvenile amaurotic idiocy (Jervis, 1959; Folch-Pi and Lees, 1959) but Cumings (1961) reported that these lipids are moderately in excess in this condition.

On the basis of the presented data and of the opinions expressed in the literature, it appears that current concepts of the pathogenesis of the amaurotic idiocies may require revision. It should be considered that the accumulation of lipids in the perikaria is neither a 'storage' nor does it necessarily indicate a disturbance of the lipid metabolism. Furthermore, the histochemically and biochemically demonstrable variations of the intraganglionic lipids may well reflect different stages of metabolic transformations of by-products effected by the viable, albeit 'diseased', nerve cells. The only definite statement which can be made about this process is that these metabolic transformations yield appreciable amounts of lipofucsin. Whether the intraganglionic formation of lipofucsin is directly related to the duration of the disease and/or the age of the patient cannot be stated, although this pigment is usually more abundant in the adult form. In a comparative study of different types of amaurotic idiocy and of gargoylism, lipofucsin could be demonstrated only in the brains of the juvenile and the adult form (Zeman and Alpert, 1960) but was absent from the neurons of brains with Tay-Sachs' disease and with gargoylism, although one patient with the latter condition was 20 years old at the time of death. In contrast to the brains of cases of juvenile amaurotic idiocy, those of infantile amaurotic idiocy and of gargoylism showed a multifold increase in gangliosides. These observations would then refute Diezel's (1957) hypothesis that the chemical composition of intraganglionic lipids in lipidosis is dependent upon age. The recent investigations of Korey and Terry 
(1961) may hold great promise for the elucidation of these metabolic problems.

Since the present patients were genetically related, it is interesting to note that whatever the enzymatic deficit in this family may be, it had little if any bearing upon the localization and the distribution of the lesions. The pronounced lipid accumulation of the neocortical cells in brains 2 and 3 was not at all matched by that in brain 1. Again, brains 2 and 3 showed a virtual absence of cerebellar cortical neurons, which were well preserved in brain 1 . Although most authors feel that cerebellar atrophy in juvenile amaurotic idiocy is the result of the ganglionic lipid storage, the few remaining cells in our cases were practically free of lipids. Thus the possibility must be considered that a process other than lipid accumulation had destroyed the cerebellar cortex. Further examples of the incongruity between the three cases can be found in the involvement of Sommer's sector, which is, incidentally, considered to be immune from the Schaffer-Spielmeyer process (Seitelberger et al., 1957-58; Escolá, 1961), and the accumulation of lipids in the visceral reticulo-endothelial cells observed in Case 3 only.

GENETIC CONSIDERATIONS The most remarkable feature of this study is the genetic relationship between the three patients. The occurrence of the same variant of amaurotic idiocy in two or more members of one sibship is well documented. In contrast, only a few reports exist on families in which members of different generations were found to be afflicted with the same type of amaurotic idiocy (Sjögren, 1931; Wyburn-Mason, 1943; Kinneir Wilson, ed. Bruce, 1955). To the best of our knowledge the occurrence of two different forms of amaurotic idiocy in one family has never been established beyond doubt. As mentioned above, the seemingly pertinent observation of Bertrand and van Bogaert (1934) was invalidated by post-mortem examination, and Case 8 of Wyburn-Mason (1943) lacks histological verification.

If juvenile and adult amaurotic idiocy are related, one should find their familial incidence more often than hitherto reported. Actually, in addition to the present report, there is only one other instance in which adult and juvenile cases may have occurred in one family but the juvenile cases have not been verified (Seitelberger and Nagy, 1958). On the other hand, it is not unusual that patients with adult amaurotic idiocy have siblings or relatives who also suffer from the adult form (Hallervorden, 1938; Kufs, 1925; Wagner, 1949; Allegranza, 1956; van Bogaert, 1953). Moreover, if one accepts that infantile amaurotic idiocy is different from the juvenile form, no adult cases should be found in a family with Tay-Sachs disease. This assumption seems to be refuted by Case 8 of Wyburn-Mason (1943), a mother of three children, the first being normal and the second affected with typical TaySachs disease. The third child was similarly affected but displayed an unusually late manifestation, the characteristic cherry-red spot appearing as late as 10 years of age. The mother (Case 8) developed mental deterioration and optic atrophy when she was 31 years old. Although not verified histologically, Wyburn-Mason felt safe in diagnosing this case as amaurotic idiocy, more specifically as an adult form of Tay-Sachs disease.

In consideration of these arguments, it appears that the adult form of amaurotic idiocy may occur in three different genetic connexions, namely, as a distinct entity, as a late form of Tay-Sachs disease, and as a late form of Batten-Spielmeyer-Vogt disease. It is noteworthy that all patients with adult amaurotic idiocy coming from families with either Tay-Sachs or with Batten-Spielmeyer-Vogt disease had, in addition to mental deterioration, optic atrophy. Patients with the autochthonous 'familial cerebral lipidosis of the adult' were sometimes mentally normal, and invariably had normal fundoscopic findings.

\section{SUMMARY AND CONCLUSION}

Three cases of amaurotic idiocy, one adult and two juvenile forms, affecting members of two different generations of one family are reported. A comparative histochemical study showed fluctuations in the staining and physico-chemical qualities of the intraganglionic lipids to such an extent that doubt is cast on current opinion as to the nature of this group of lipidoses. The observation which was most inconsistent with presently accepted viewpoints was a lack of correlation between sudanophilia, fat solubility, and affinity for Amino black B10.

As a result of this study, there is additional support for the previously offered hypothesis by one of the authors (Hoffman, 1958) that the juvenile amaurotic idiocy of Batten-Spielmeyer-Vogt and the adult form of Kufs are closely related if not modified forms of the same fundamental process. Furthermore, the concept that the adult form of amaurotic idiocy is an expression of the mitigated intensity of the metabolic disorder (Seitelberger and Nagy, 1958) has been strengthened.

It is the belief of one of the authors (W.Z.) that the investigation also supports the theory first presented by Wolman (1961) that amaurotic idiocy is but the phenotypical expression of a variety of genetically different metabolic disturbances. 
We are grateful to Miss Norine Appel, Mrs. Dorothy Meyer, and Mrs. Norma Hoggatt for performing the histochemical techniques, to Mr. Joe Demma for preparing the photomicrographs, and to Mr. James Glore for preparing the pedigree. The study was in part supported by the Indiana Department of Mental Health.

\section{REFERENCES}

Allegranza, A. (1956). Acta neurol. (Napoli), 11, 596.

Bertrand, I., and van Bogaert, L. (1934). Encéphale, 29, 505.

van Bogaert, L. (1953). Bull. Acad. roy. Med. Belg., VIe Ser. 18, 9.

, and Borremans, P. (1937). Z. ges. Neurol. Psychiat., 159, 136.
Cumings, J. N. (1961). Scientific Aspects of Neurology. Williams and Wilkins, Baltimore.

Diezel, P. B. (1957). Die Stoffwechselstörungen der Sphingolipoide. Springer, Berlin-Göttingen-Heidelberg.

- (1960). Modern Scientific Aspects of Neurology. Ed. J. N. Cumings. Arnold, London.

Escolá, J. (1961). Arch. Psychiat. Nervenkr., 202, 95.

Fine, D. I. M., Barron, K. D., and Hirano, A. (1960). J. Neuropath., 19, 355.

Folch-Pi, J., and Lees, M. (1959). A.M.A. J. Dis. Child., 97, 730.

Friedrich, G. (1957). In Handbuch der speziellen pathologschen Anatomie und Histologie, ed. O. Lubarsch, F. Henke, and R. Rössle, band 13. Ed. W. Scholz, teil 1, bandteil A, p. 540. Springer, Berlin.

Hallervorden, J. (1938). Verh. Dtsch. path. Ges., 31, 103.

Hanhart, E. (1954). Acta Genet. med. (Roma), 3, 331

Higier, H. (1897). Disch. Z. Nervenheilk., 9, 1.

Hoffman, J. (1958). Acta psychiat. scand., 33, 336.
Hoffman, J. and Riepenhoff, J. P. (1957). Amer. J. ment. Defic., 62, 67. Jervis, G. A. (1959). A.M.A. J. Dis. Child., 97, 663.

Klenk, E., and Langerbeins, H. (1941). Hoppe-Seylers Z. physiol. Chemie, 270, 185.

Korey, S. R., and Terry, R. (1961). Meeting of the American Academy of Neurology, April, 1961.

Kufs, H. (1925). Z. ges. Neurol. Psychiat., 95, 169. (1931). Ibid., 137, 432.

McCluer, R. H., Coram, E. H., and Lee, H. S. (1962). J. Lipid Res., in press.

Norman, R. M. (1958). Neuropathology. Ed. J. G. Greenfield. Arnold, London.

Ponga, R. P. R. (1960). Inform. psiquia., 5, 11.

Sandifer, P. (1959). Biochemical Aspects of Neurological Disorders. Ed. J. N. Cumings and M. Kremer, p. 191. Blackwell, Oxford.

Schaffer, C. (1930). Arch. Neurol. Psychiat., 24, 765.

Seitelberger, F., and Nagy, K. (1958). Dtsch. Z. Nervenheilk., 177, 577.

- Vogel, G., and Stepan, H. (1957-58). Arch. Psychiat. Nervenkr., 196, 154.

Sjögren, T. (1931). Hereditas (Lund), 14, 197.

Sjövall, E. (1934). Verh. dtsch. path. Ges., 27, 185.

Spielmeyer, W. (1905). Neurol. Zbl., 24, 1131.

- (1922). Histopathologie des Nervensystems. Springer, Berlin. (1929). Jb. Psychol. Neurol., 38, 120.

Svennerholm, L. (1956). Acta Soc. Med. upsalien., 61, 75.

Vogt, H. (1909). Arch. Kinderheilk., 51, 1.

Wagner, E. (1949). Klin. Mbl. Augenheilk., 114, 37.

Wilson, S. A. Kinnier (1955). Neurology, 2nd ed., ed. A. Ninian Bruce. Vol. 2. Williams and Wilkins, Baltimore.

Wolman, M. (1961). Acta neuropath. (Berl.), 1, 73.

Wyburn-Mason, R. (1943). Brit. J. Ophthal., 27, 145.

Zeman, W., and Alpert, M. (1960). Presented I Int. Congress Histochemistry and Cytochemistry, Paris, August 1960. 